\title{
Integrating issues of sexuality into Egyptian family planning counseling [Arabic]
}

Frontiers in Reproductive Health

Follow this and additional works at: https://knowledgecommons.popcouncil.org/departments_sbsr-rh How does access to this work benefit you? Let us know!

\section{Recommended Citation}

"Integrating issues of sexuality into Egyptian family planning counseling," Summary of Key Findings [in Arabic]. Cairo: Population Council, 2000. 


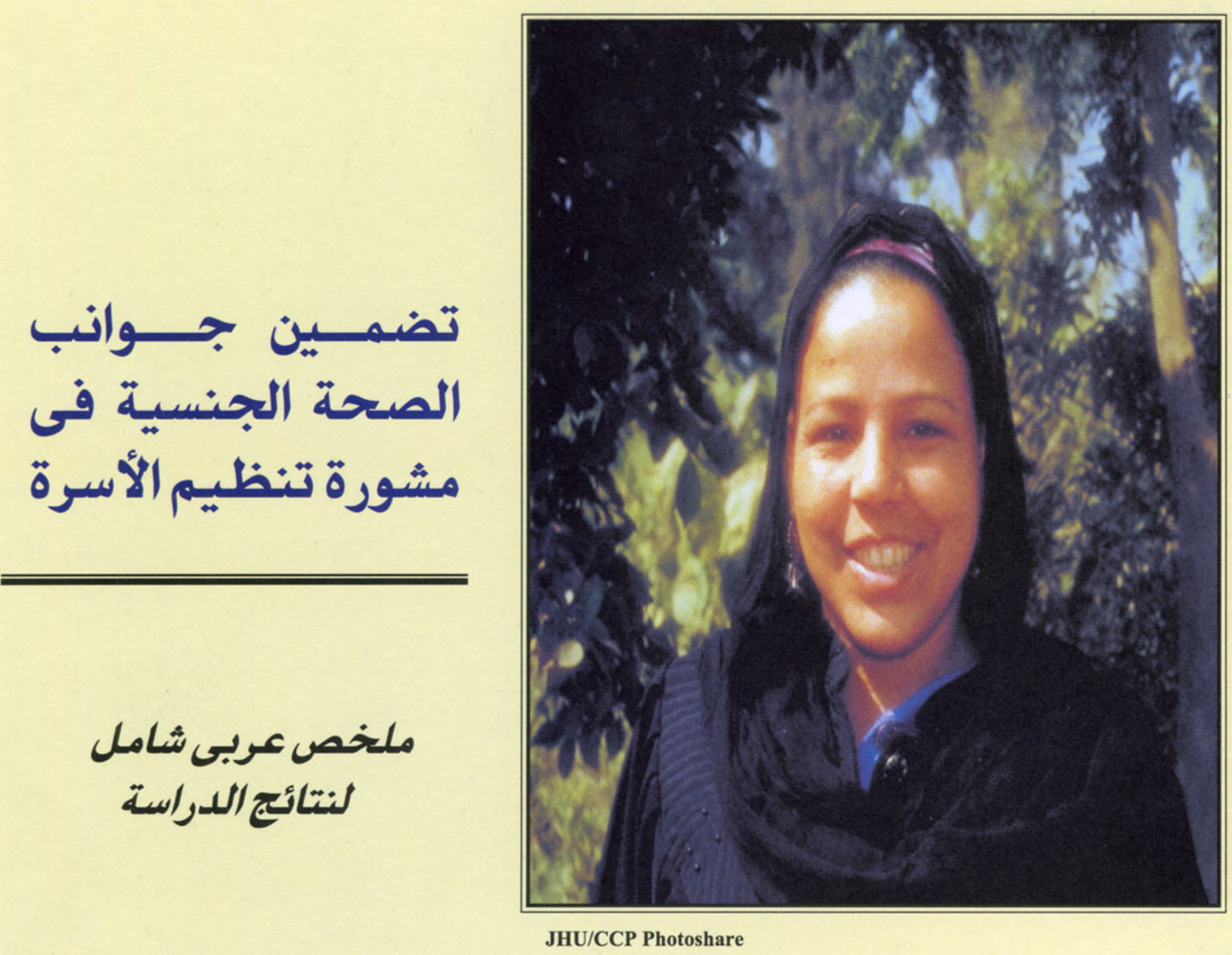

مشروع آفاق جديدة بالصحة الإنجابية المجلس الدولى للسكـان

1 Population Council

7 Frontiers 
رحب كل من مقدمي خحمات تنظيم الأسرة والسيدات المترددات على مراكن تنظيمر الأسرة

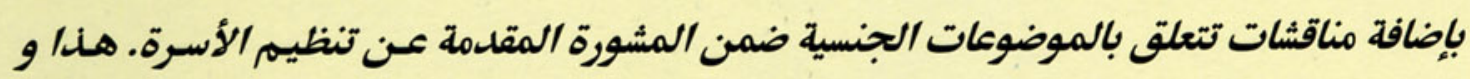

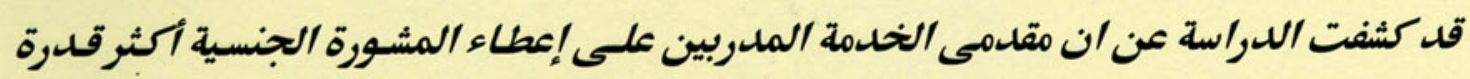

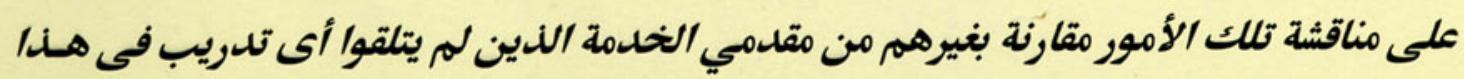

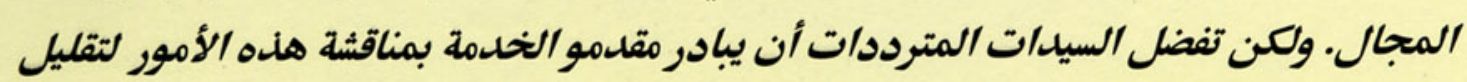
شعور السيدة بالحرج .

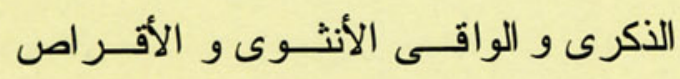

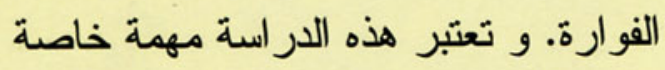
في مجتمع ذو تقاليد إجتماعية محافظة فيما

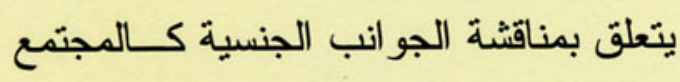
المصرى. وقد حاولت الدر اســــة الإجابـــة

على الأسئلة التالية:

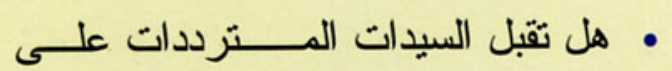
مر اكز تنظيم الأسرة في مصر مناقشة القضايا المتعلقة بالشئون الجنسية أثناء

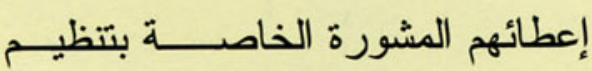

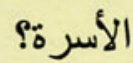
• هل يتقبل مقدمو خدمة تنظيم الأســـرة الحصول على تدريب يتعلق بالشـــئون

$$
\text { و الجو انب الجنسية؟ على بكريب }
$$

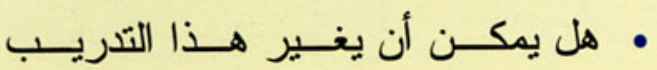
اتجاهات و اسلوب مقدمى الخدمة فـي لئي تقديم المشورة؟ • ما مدى إقبال المترددات على إبـتخدام الوسائل الموضعيه؟ مأ مدال

\section{منهجية الار اسة:}

تم إجر اء هذه الدر اسة فى ســـتـة مر اكــز

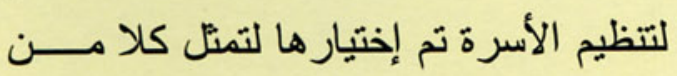

\section{خلفية عامة:}

تمثل المشورة أهمية كبرى في زيادة أعداد السيدات المو افقات على اســـخدام وســائل تنظيم الأسرة إضافة إلى أهميتها من أجــلـ

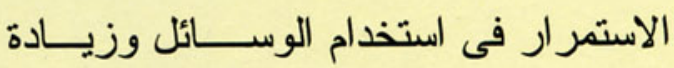

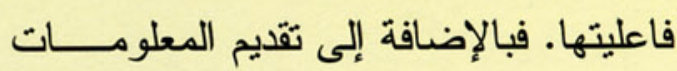

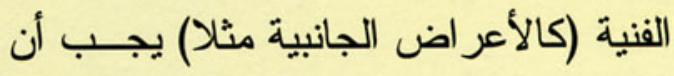

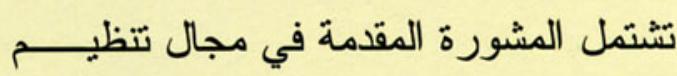

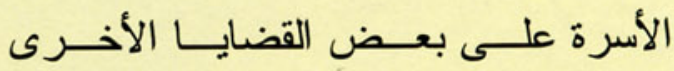

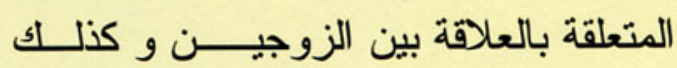

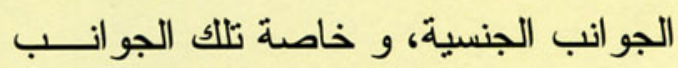

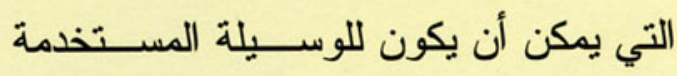

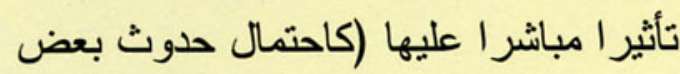

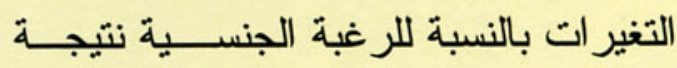
استخدام بعض الوسائل الهرمونية). و هــــه المشورة ضرورية خاصة عنــد اسـتـعمال الوسائل الموضعية أثناء الإتصال الجنسـي.

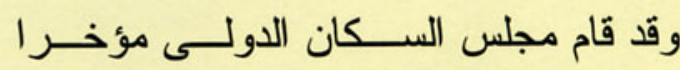

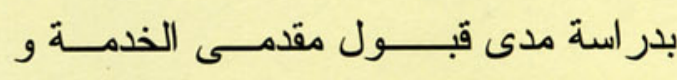

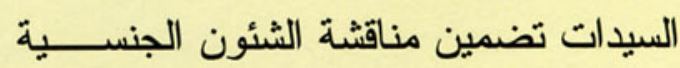

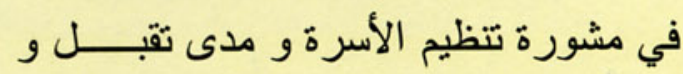
امكانية استخدام الوسائل الموضعيه كالو اقى القيرة 
سنة أسابيع من إتمام تللك الدورة، و الــــــى كشف عن مدى تأثير التذريب على مواقفهم تجاه الوسائل الموضعية و علـــــى إعطــاء المشورة فى النواحى الجنسية وذلك عــــن طريق إستخدلم مؤشر ات متعددة البنــــود. و بالاضافة إلى كل ذلك فقد تم قياس التغيير في أسلوب إعطاء المشورة بشكل كيفي عن

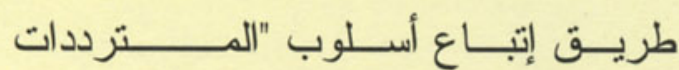
المجهو لات" (mystery clients) وآخــر كمي عن طريق اجـــر اء المقــابلات مـــع

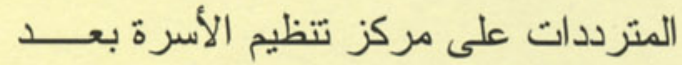
الحصول على الخدمات و قبــــلـ مغـــادرة

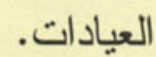

وقد تم قياس مدى تقبــــــلـ المــترددات

لإستخدام الوسائل الموضعية في العيــادات الست محل الدراسة، عن طريـــن اجــر اء المقابلات معــــن حيــث اثــــملت عينــة الدراسة على ب.0 سيدة من المــــرددات

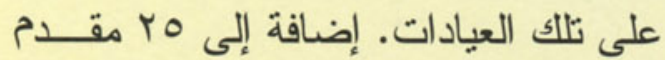
للخدمة وتضمنت عينة مقدمي الخدمة جميع الأطباء و الممرضنات و مقدمي المشـــــورة العاملين في تلك العيــادات. أمـــا بالنســـبة للمنز ددات فقـــد تضنمنـــت العينــة جميــع السيدات اللاتي تزددن على العيادات محـلـ

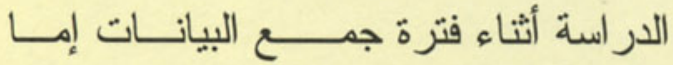

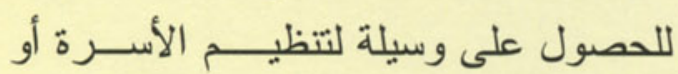
لتغيير الوسيلة المستخدمة وذللك للتعــرف على مدى رضائهن عن سلوكيات مقدمــى الخدمة وما اذا كـن شعرن بالحرج اثثــــــاء اجراء اى مناقشات حول الأمور الجنسية.
وز ارة الصحة و السكان ومشروع تحســين

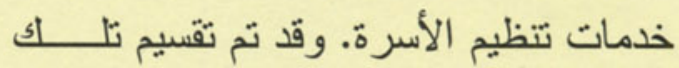

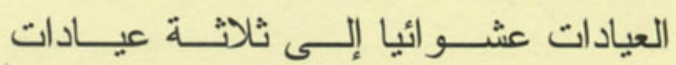

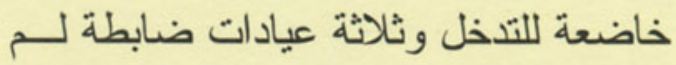
يطبق عليها التذخل. وقد حصل الأطبـــــاء و الممرضــات و مقدمــو المشــورة فــي العيادات الستة على دورة تتشـــبطية عـن وسائل تتظيم الأسرة مدتها ثلاثة أيام. كمـــا حصل مقدمو الخدمة بالعيادات الخاضعــــة للتذخــلـل على دورة تذريبية أخرى لمــــــدة

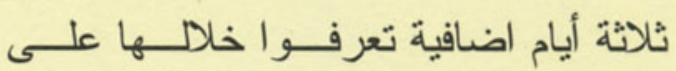

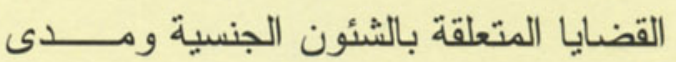
العلاقة بينها وبين استخدام وسائل تتظي. الأسرة و تأثير ها على استخدام الوسائل.

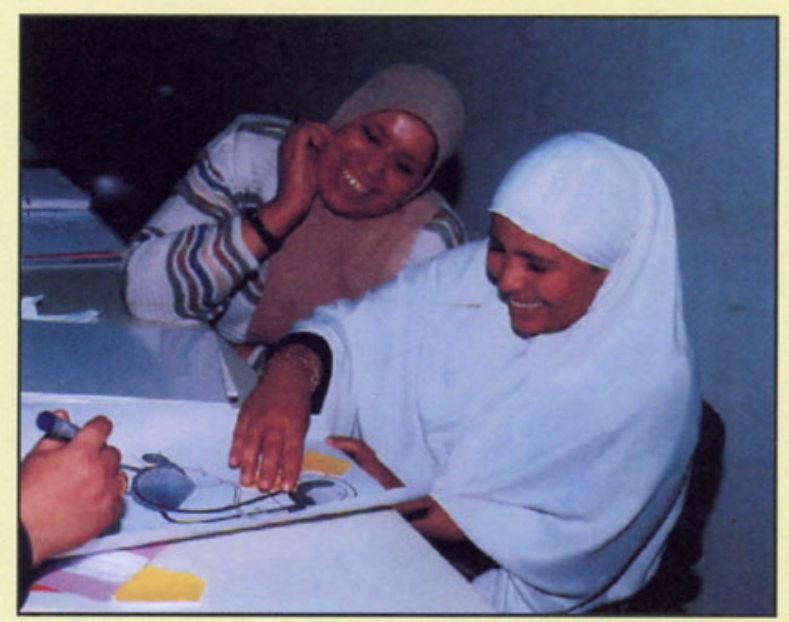

جانب من الأنشطة العملية للدورة التدريبية لمقدمى الحخدمة

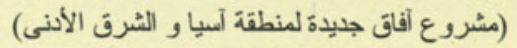

و تم التعرف على مدى تقبل مقدمــــى الخدمة الحصول علــــى تذريــب يتعلــث بالجو انب الجنسية من خلال ملاحظة ردود افعالهم أثتاء تلقيهم التذريب و التعرف على بلى آرائهم و التى عبروا عنها من خلال نماذج الثقييم الخاصة بالدورة التذريبية. كما قـــام مقدمو الخدمة باسنكمال استبيان خاص بعد 
"لو الدكتورة ساكتا الأسئلة دي خنقولها على مشاكلنا لكن غير كده

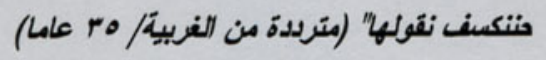

"فيه في بعض الأحيان مواضيع حساسة أكسف أقوالها لاكتوق راجل،

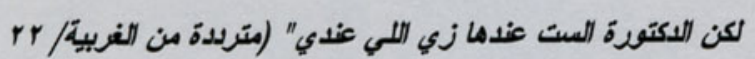

"بعض الأحيان ما بيحصلث جماع مع جوزي بسبب اللولب (النزيف)

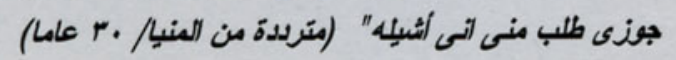

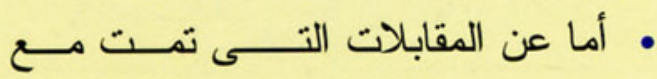

المترددات على مر اكز تتظيم الأســرة بعد الحصول على الخدمة فقد أظهرت

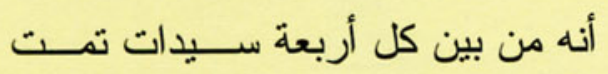

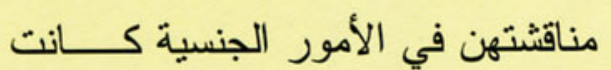
هناك ثلاثة سيدات لم تشعرن بــالحرج لإجر اء تلك المناقشة (العــــد ع V ا) .

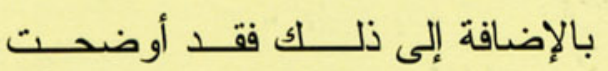
الدر اسة أن السيدات اللاتي نم مقابلتهن

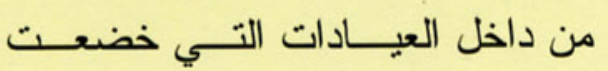
للتـخل كن أكثر إثارة إلى أن مق لـــدم

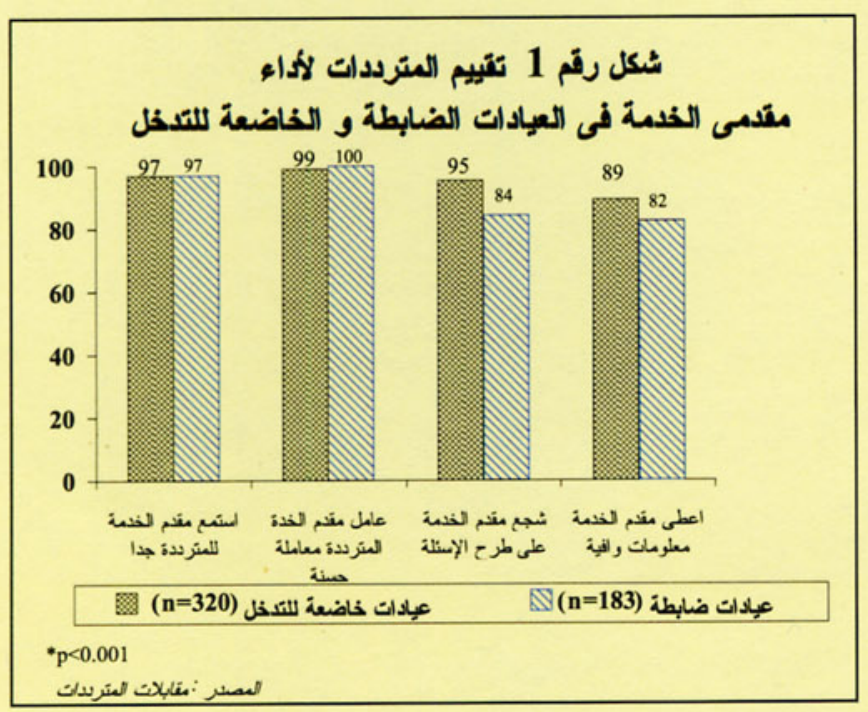

و قد اختيرت سبعة مترددات مجـــــــــات لات على العيـــــادات و (mystery clients) يطلبن الخدمة و لكن تــم التتســيق معــــن ليلغن فريق البحث بشأن أسلوب مقدمـــى لخى الخدمة في إعطاء المشورة. و هذه الطريقة

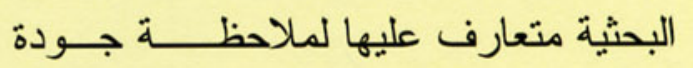
الخدمات. كما تم عقد خمس حلقات نقاشــية استهدفت قياس تقبل المترددات للمشـــــورة الجنسية.

\section{نتائج الدر اسةة:}

• أظهرث نتائج الدر اسة تقبل المـترددات على تتظيم الأسرة في مصر للمشـورة

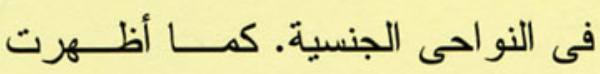
أن هــــالك العـــــديد من المشكــــلات و التساؤلات المتعلقة بالأمور الجنسية تتعرض لها السيدات محل الدر اســــة. فقد أشارت المشاركات في الحلقــــات النقاشية إلى رغبتهن في التحدث مـــع مقدمى الخدمة بشأن ما يو اجهنه مـــنـ مشكلات جنسية مع ازو اجهن إلا أنهن يشعرن بالخجل لأن يبــادرن بطــــرح

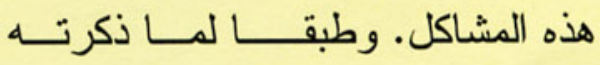
المشاركات فإنه إذا ما ســــأل مقدمـــو الخدمة السيدات بعض الأسئلة التقليدية كالعلاقة الجنسية مع الزوج، فان ذلــك كالك سيساعد كثير ا. كذلك تفضل الســبدات أن يكون مقدمو الخدمة مـــن الإنــاث وذللك عند مناقشة المشكلات الجنســية حيث سيقلل هذا من الشعور بالحرج. 
إيجابية فيما يتعلق بالوسائل الموضعية الثلاث محل الدر اسة (الواقي الذكري و الواقي الانثوى و الأقر اص الفوارة) في العيادات التي خضعت للتـخل مقارنــة بالعيادات الضابطة. إلا أنه لم يكن لما تلقاه مقدمو الخدمة من تدريب أي أثر ملحوظ في تغيير اتجاهاتهم نحو تقديـم المشورة الجنسية ـ فكثير ا من مقدمسـي الخدمة بالعيادات التي خضعت للتذخل لا يزالوا يشعروا بالحرج لمناقشــــة الشئون الجنسية مع المترددات. كمـــــا لايز ال هناك بعض مقدمـــي الخدمــة

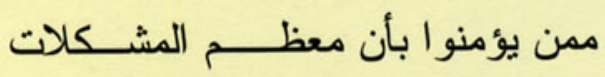

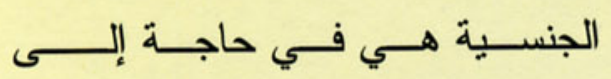
متخصصين لحلها إضـافة إلى إيمانــــــي

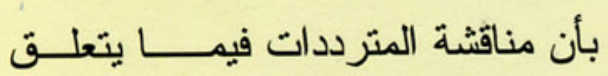
بالجوانب الجنسية سيسبب لهم حرجــا كبير أوضحت الدر اسة نتائج غير منوقعة بخصوص اثر التدريب على ما يتبعـــ

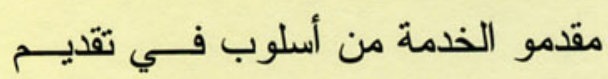
المشورة الخاصة بالوسائل الموضعية. فعلى الرغم من أن مقدمــــي الخدمـــة بالعيادات الخاضعة للتدخل كانو أكثر ذكر للأقر اص الفوارة مقارنة بالعيادات

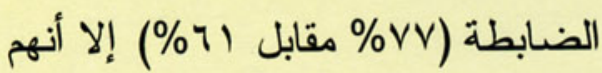
أعطوا معلومات أقل عن الو اقي الأنثوى وعن الأقر اص الفوارة مقارنة بمقدمى الخدمة بالعيادات الضابطة. وقد يرجع
الخدمة شجعهن على طر ح ما بـردن

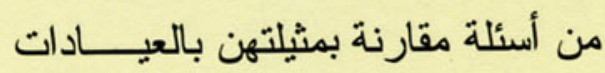
الضـابطة (90\% مقابل ع^\%) كمــــا أشرن إلى تلقيهن لكافــــة المعلومـــات التي كن يتوقعنها من مقدمى الخدمـــــة

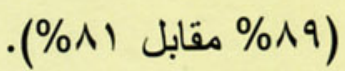
• أظهرت النتائج قبول مقدمي الخدمة لما تلقوه من تدريب عن مناقشة الجوانــب الجنسية كجزء مــن مشـــورة تتظيــم الأسرة. وقد اتضح من ملاحظة ردود افعالهم تجاه الدورة التدريبية إهنمامهم الكبير بتلك الجو انب. ففــــي بــاديء الأمر أظهر بعض مقدمــــى الخدمــــة

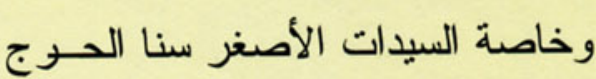

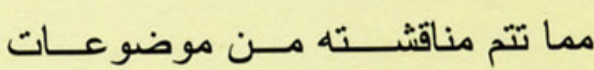
إضافة إلى رفضهن المشاركة فـي أى ملى مأى من تلك المناقشات. ولكن أظهر التقييم الخاص بالدورة التدريبية إضافة إلــى ما تم استخلاصه من إستبيان مقدمــي

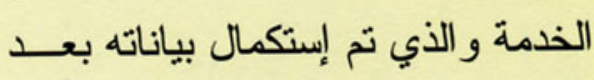

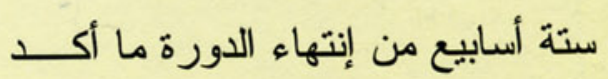
عليه مقدمو الخدمة من رضاء تام عن تلك الدورة التذريبية حتى أنـــــهم قــد اقترحوا الحصول على دورات اخـرى للتذريب على حل المشكلات الجنسية.

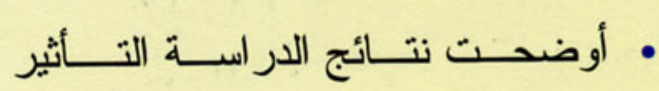
الإيجابي للــدورات التذريبيـــة علــى موقف مقدمي الخدمة تجاه الوســــــائل الموضعية. هذا وقد كانت النتائج أكثر 


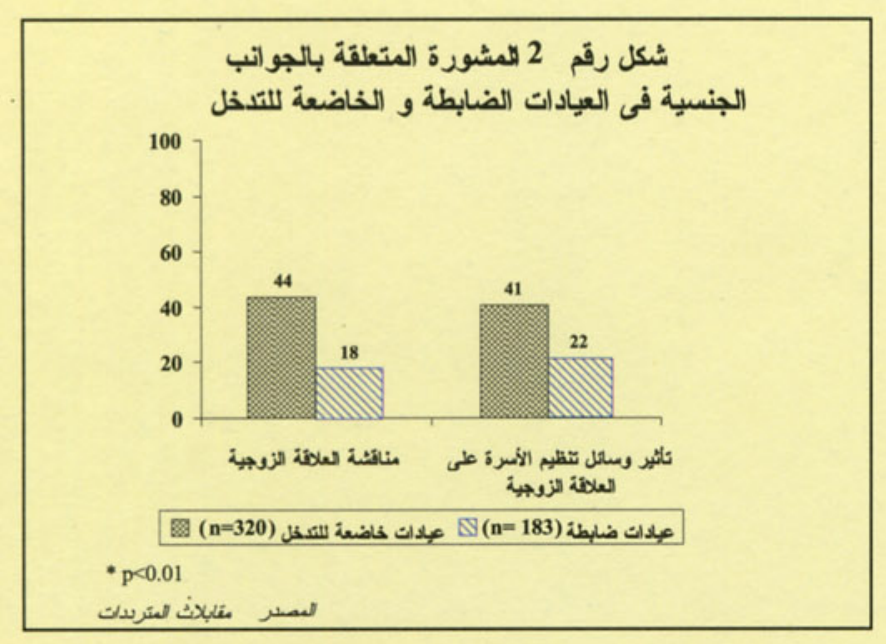

مكونات المشورة الخاصـــة بالثـــئون الجنسية حيث لم تكن لــــدى مقدمــي

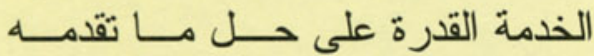

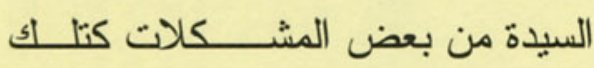
المتعلقة بفقـــدان الرغبـــة الجنســية ،

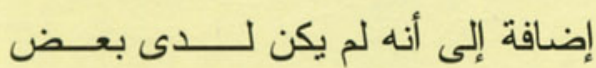
مقدمي الخدمة معرفة تامة بما بحــدث من نغييرات في الرغبة الجنسية نتيجة إستخذام بعض الوســـائل الهرمونبــــة.

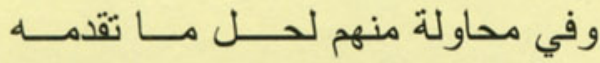

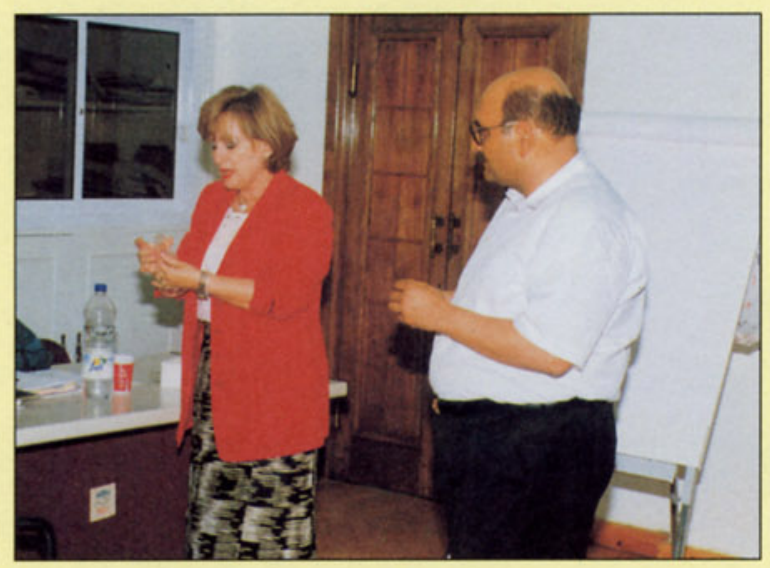

د. معالى جميعي و د. عبد العزيز الشوبرى يشرحان طريقة استخدام (مشروع آفاق جديدة لمنطقة آسيا والشرق الأدن)
السيدات من شــــوى نتعلــق بفقـــدان الرغبة الجنسية على ســــبيل المثـــال فكثير ا ما كانوا يوجهون اللــوم إلــى ذللك إلــى أن مقدمــي الخدمـــة فـى العيادات التى تم فيها تدخل قد ركـزو التي

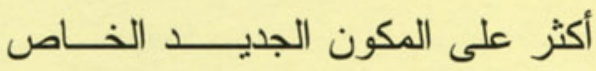

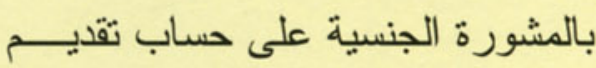
المشورة الخاصة بالوسائل الموضعية. • و قد كان للتذخل تأثير إيجابيا عل

أسلوب مقدمي الخدمة فـــــي إعطــــاء المشورة اللازمة. فقد كــــانت نســبة المبة المنرددات اللاتى حصلن على مشورة حول ثأثثر وســــيلة تنظيــــ الأســرة المختارة على العلاقات الجنسية اعلىى

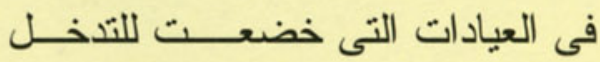

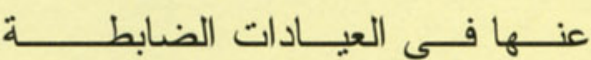
\% م مقابل r r r ) كما ذكرت نسبة ) اعلى من المنرددات انه جرت مناقشة

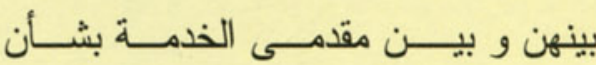
الموضو عات الجنسية بصفــــة عامـــة

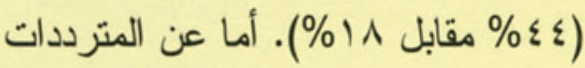
المجهو لات (mystery clients) فقـد ذكرن أن مقدمي الخدمة بالعيادات التــي خضعت للتندخل كانوا اكثر تـــررا فـى مناقشة القضايا الجنسية مـــع المــترددات و انهم شجعوا السبدات على عــرض مـــا يو اجهـــه من مشكلات تثعلق بشــــــونهن الجنسية. إلا أن هـــــــاء المـــرددات اشرن الى بعض عناصر النقص فــي 


\section{تتضمن توصيات الدر هذة الدر اسة ما يلى:}

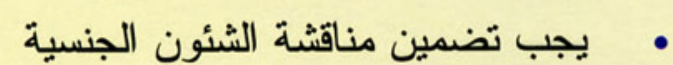

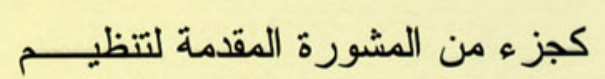
الأسرة. من هنا يجـــب أن تثـــنـل

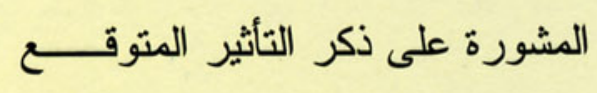
لكل وسيلة على العلاقة الجنسية بيـنـن

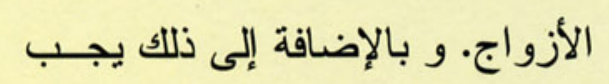
أن يتضمن أخذ التاريخ الصحى مسن لــن

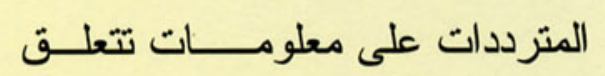
بالعلاقة الزوجية.

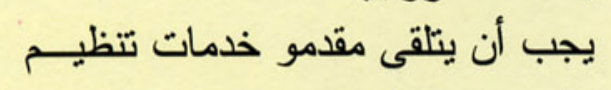

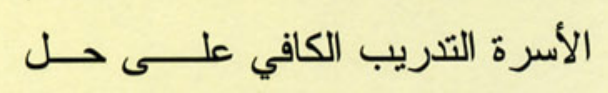

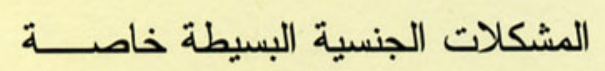

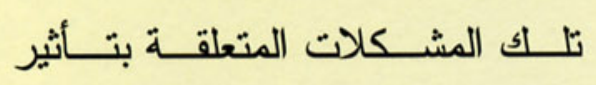
إستخدام وسائل تنظيم الأسرة.

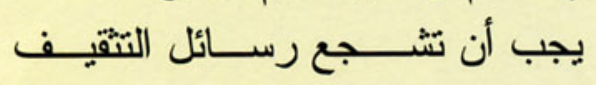

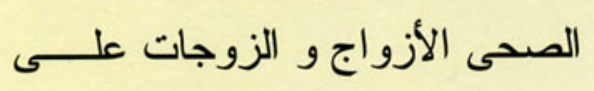

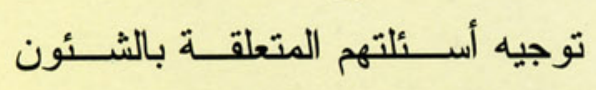

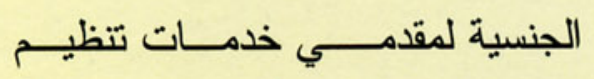
الأسرة.

لابد من تقوية الربط بيــن عبــادات تنظيم الأسرة والمستشفيات الجامعينة

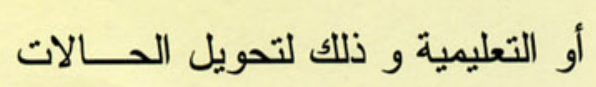
التي تشكو من مشكلات جنسية معقدة و التى تنوق معرفة و تدريب مقدمى من منالية خدمات تنظيم الأسرة.

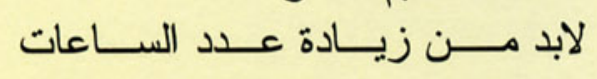
المخصصة لتنريس العلوم الجنســية لطلاب كليات الطب فى الجامعــــات المصرية. - ابل
السيدة نفسها بدلا من الســــؤال عــن

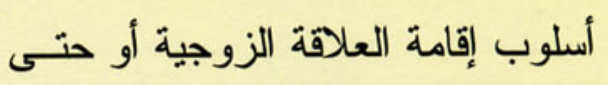

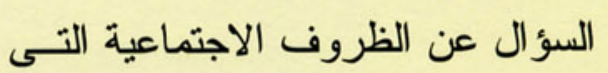
تتم من خلالها تلك العلاقة.

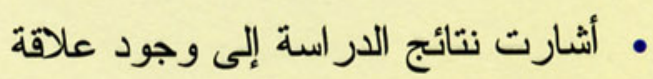
قوية تربط بين تدريب مقدمى الخدمسـة على تقديم المشورة الجنسية ومو افقــــة

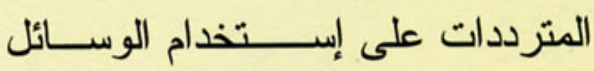

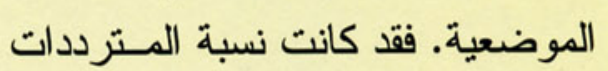

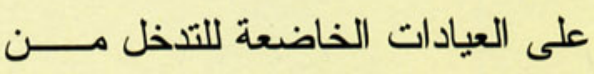
اللأيى حصلن على وسيلة موضعيــــة

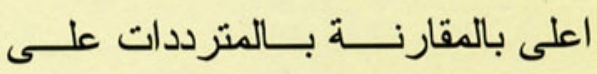

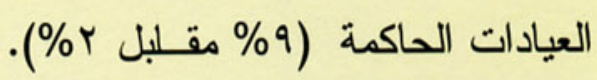

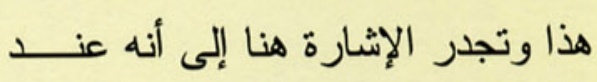

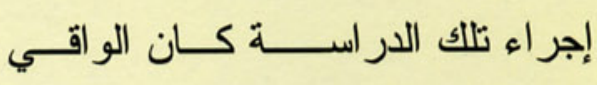
الذكري يمثــلـ الوســيلة الموضعيــة الوحيدة المتو افرة فى معظم العيـادات. هذا ولم يكن هناك فارق كبير بالنسـبـة

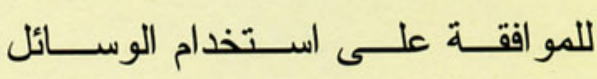

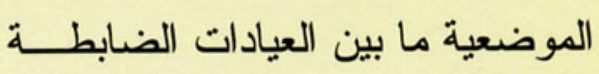

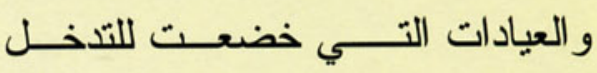
(ابr\%). إلا أن اقبال المترددات على خلى

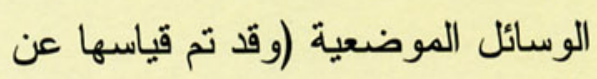

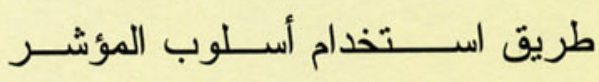

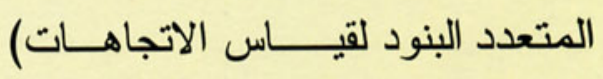

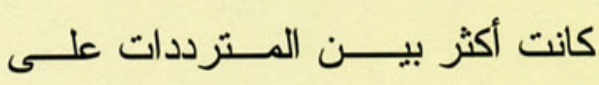

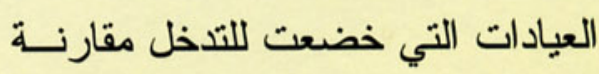
بالمترددات على العيادات الضابطة. 
لمزيد من المعلومات عن هذه الدراسة او للحصول على نسخة من التقرير النهائى باللغة الاجليزية برجاء الاحصال بالأستاذة/ جيهان حسنى - سكرتيرة مشروع آفات جليدة بالمجلس الدولى للسكان

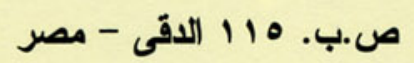

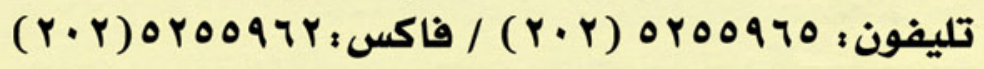

\section{E-mail:frontiers@pccairo.org}

يتم تمويل مشروع "آفاتى جليدة فى الصحة الاجابية" عن طريق مكتب السكان بالوكالة الأمريكية للتبية الدولية ضمن اتفات التعاون رقم: HRN-A-00-98-00012-00 